\title{
Risk Assessment of Importation and Local Transmission of COVID-19 in South Korea: Statistical Modeling Approach
}

Hyojung Lee ${ }^{1}$, PhD; Yeahwon Kim², BA; Eunsu Kim² ${ }^{2}$ BA; Sunmi Lee ${ }^{2}, \mathrm{PhD}$

${ }^{1}$ National Institute for Mathematical Sciences, Daejeon, Republic of Korea

${ }^{2}$ Kyung Hee University, Yongin-si, Republic of Korea

Corresponding Author:

Sunmi Lee, $\mathrm{PhD}$

Kyung Hee University

1732 Deogyeong-daero, Giheung-gu

Yongin-si, 17104

Republic of Korea

Phone: 82312012409

Email: sunmilee@khu.ac.kr

\section{Abstract}

Background: Despite recent achievements in vaccines, antiviral drugs, and medical infrastructure, the emergence of COVID-19 has posed a serious threat to humans worldwide. Most countries are well connected on a global scale, making it nearly impossible to implement perfect and prompt mitigation strategies for infectious disease outbreaks. In particular, due to the explosive growth of international travel, the complex network of human mobility enabled the rapid spread of COVID-19 globally.

Objective: South Korea was one of the earliest countries to be affected by COVID-19. In the absence of vaccines and treatments, South Korea has implemented and maintained stringent interventions, such as large-scale epidemiological investigations, rapid diagnosis, social distancing, and prompt clinical classification of severely ill patients with appropriate medical measures. In particular, South Korea has implemented effective airport screenings and quarantine measures. In this study, we aimed to assess the country-specific importation risk of COVID-19 and investigate its impact on the local transmission of COVID-19.

Methods: The country-specific importation risk of COVID-19 in South Korea was assessed. We investigated the relationships between country-specific imported cases, passenger numbers, and the severity of country-specific COVID-19 prevalence from January to October 2020. We assessed the country-specific risk by incorporating country-specific information. A renewal mathematical model was employed, considering both imported and local cases of COVID-19 in South Korea. Furthermore, we estimated the basic and effective reproduction numbers.

Results: The risk of importation from China was highest between January and February 2020, while that from North America (the United States and Canada) was high from April to October 2020. The $\mathrm{R}_{0}$ was estimated at 1.87 (95\% CI 1.47-2.34), using the rate of $\alpha=0.07$ for secondary transmission caused by imported cases. The $\mathrm{R}_{\mathrm{t}}$ was estimated in South Korea and in both Seoul and Gyeonggi.

Conclusions: A statistical model accounting for imported and locally transmitted cases was employed to estimate $\mathrm{R}_{0}$ and $\mathrm{R}_{\mathrm{t}}$. Our results indicated that the prompt implementation of airport screening measures (contact tracing with case isolation and quarantine) successfully reduced local transmission caused by imported cases despite passengers arriving from high-risk countries throughout the year. Moreover, various mitigation interventions, including social distancing and travel restrictions within South Korea, have been effectively implemented to reduce the spread of local cases in South Korea.

(JMIR Public Health Surveill 2021;7(6):e26784) doi: 10.2196/26784

\section{KEYWORDS}

COVID-19; transmission dynamics; South Korea; international travels; imported and local transmission; basic reproduction number; effective reproduction number; mitigation intervention strategies; risk; assessment; transmission; mitigation; strategy; travel; mobility; spread; intervention; diagnosis; monitoring; testing 


\section{Introduction}

The COVID-19 outbreak has affected people worldwide. A novel virus named SARS-CoV-2 was identified as the pathogen responsible for the outbreak of COVID-19 [1]. The common symptoms of COVID-19 include fever, dry cough, fatigue, chills, headache, and sore throat. Furthermore, severe symptoms of COVID-19, including high fever, severe cough, and shortness of breath, are often indicative of pneumonia [2]. The first case of COVID-19 was reported in Wuhan, China, in early December 2019. On March 11, 2020, the World Health Organization (WHO) declared the outbreak a global pandemic [3]. As of October 31, 2020, a total of 45,551,965 confirmed cases and more than 1,189,306 deaths were reported in 214 countries worldwide. The world has experienced a couple of epidemics caused by coronaviruses from the same family as SARS-CoV-2, such as severe acute respiratory syndrome (SARS) caused by SARS-CoV in 2003 and Middle East respiratory syndrome (MERS) caused by MERS-CoV in 2012, which had a large impact similar to that of the currently ongoing COVID-19 pandemic. However, the impact of COVID-19 is different in many aspects and has been more devastating than that of the other two outbreaks [4-6]. Due to the substantial growth of international travel, the complex network of human mobility has allowed pathogens to spread globally within a short time scale. In particular, the recent new COVID-19 variants have motivated the implementation of strengthened border control and lockdowns worldwide [7].

In this regard, most researchers have confirmed that COVID-19 was exported via air travel from mainland China. Researchers have developed many mathematical, statistical, and computational models to analyze air traffic data and estimate the consequent effects. Many researchers have investigated COVID-19 transmission dynamics in various ways. They have analyzed the characteristics of pathogen transmission cases in various experiments using elaborate computational models; their findings have enlightened us on how COVID-19 may affect us in the future. International air travel volume has been significantly related to the spread of COVID-19 worldwide. A network-driven model of global spread employed air traffic data to demonstrate and compare the impacts of the H1N1 epidemic in 2009 and the SARS epidemic in 2003 [8]. Furthermore, the risk of MERS-CoV exportation worldwide was evaluated by incorporating seasonal air traffic flows and the time-varying incidence of cases in Middle Eastern countries [9].

Various studies have investigated the global spread of COVID-19 during the early stages of the pandemic. One study examined how COVID-19 was imported into Europe by analyzing air traffic data [10]. Another study investigated the risk of transmission of COVID-19 through flights from four major cities in China (Wuhan, Beijing, Shanghai, and Guangzhou) to the passengers' destination countries [11]. The study identified a risk index of COVID-19 transmission based on the number of travelers to destination countries, weighted by the number of confirmed cases in the departed city as reported by the WHO. The importation risk of COVID-19 cases by air travel from infected areas in China was assessed [12]. The risk before and after the travel ban in Hubei province was compared. Travel restrictions and border control measures have been enforced in China and other countries to limit the spread of the disease [13]. The results of a previous study showed that the daily risk of exporting a minimum of one COVID-19 case from mainland China via international travel exceeded $95 \%$ on January 13, 2020 [13].

Furthermore, the risk of imported COVID-19 cases was investigated in China by measuring a risk index from inbound international flights in previous studies $[14,15]$. These studies evaluated policy implications based on the index to adjust international air travel restrictions dynamically. Another study analyzed imported cases of COVID-19 in Taiwan in terms of characteristics, infection source, symptom presentation, and route of identification of imported cases [16]. The study confirmed that the strict enforcement of countermeasures was effective in preventing community transmission. The risks of both importation and exportation of COVID-19 have been investigated in a previous study [17]. The study evaluated the risk of importation and exportation of COVID-19 in all airports of 73 countries during the early stages of the pandemic until March 3, 2020.

The complex network of human mobility has been identified as an essential factor responsible for the rapid spread of COVID-19 globally. Due to the special situation between South Korea and North Korea, international flights are the most common way to enter South Korea. In particular, due to a large number of international travelers from China, South Korea was one of the earliest countries to experience a COVID-19 outbreak. In the absence of vaccines and treatments, South Korea implemented and maintained stringent interventions such as large-scale epidemiological investigations, rapid diagnosis, case isolation, contact tracing, quarantine, and social distancing. Despite the overall dramatic decrease in international flights, there is still a constant inflow of flights from high-risk countries. Therefore, the risk of COVID-19 in South Korea must be assessed.

In this study, we investigated the impact of international travel on the local transmission dynamics of COVID-19 in South Korea. First, we identified the relationship between the number of international travelers and country-specific confirmed cases of COVID-19. We computed the country-specific importation risk of COVID-19, accounting for the number of travelers entering South Korea, the number of confirmed cases in the originating countries, and the population of the originating countries. Second, statistical modeling was employed to capture the impact of secondary transmission caused by both imported and local cases of COVID-19 and determine the basic reproduction number $\left(R_{0}\right)$ and the effective reproduction number $\left(R_{\mathrm{t}}\right)$. Finally, we assessed the impact of imported cases on local transmission of COVID-19.

\section{Methods}

\section{Epidemiological Data}

We analyzed country-specific epidemiological data on COVID-19 cases and international travel volume in South Korea from January to October 2020. First, data on the number of 
confirmed COVID-19 cases in South Korea were extracted from the Korea Disease Control and Prevention Agency (publicly available data) [18]. The epidemiological data included the dates of confirmation, dates of symptom onset, and transmission classification (local transmission/imported cases) [19]. Second, data on the monthly number of passengers entering South Korea in 2019-2020 were gathered from Incheon International Airport (publicly available data) [20]. Third, data on the number of confirmed cases of COVID-19 from the countries of origin were collected from the WHO situation report [21] and countries' populations were obtained from [22]. The country-specific data are presented in Table S1 and Figures S1-S5 in Multimedia Appendix 1.

\section{Epidemiological Characteristics of COVID-19 Transmission Dynamics in South Korea}

We have presented the epidemic curves of local and imported cases in South Korea in Figure 1A and in Seoul and Gyeonggi in Figure 1B. Most COVID-19 cases occurred in March 2020 (due to the explosive outbreaks in Daegu and Gyeongbuk), and the number of cases in Seoul and Gyeonggi increased steadily from May 2020, leading to a larger outbreak in September 2020.
Figure 1B shows the epidemic curve in Seoul and Gyeonggi along with the timeline of screening and quarantine interventions (green box) and social distancing interventions (gray box). The list of selected interventions is presented in Table S2 in Multimedia Appendix 1. The COVID-19 transmission dynamics in South Korea showed spatial heterogeneity. There were two major hotspots. First, the early outbreak was primarily in the Daegu and Gyeongbuk areas from February to April 2020 due to the Shincheonji Church-related clusters, as shown in Figure $1 \mathrm{~A}$ and reported previously [23,24]. Second, the late outbreak was primarily in the Seoul and Gyeonggi areas in September and November 2020, as it was triggered by the Sarangjeil Church-related gathering on August 15, 2020, as shown in Figure 1A.

The timeline of the administrative measures implemented in South Korea is shown in Figure 1B and Table S2 in Multimedia Appendix 1. The Korean government, Seoul, and Gyeonggi implemented administrative countermeasures in response to the COVID-19 outbreak, including guidelines for entry restrictions followed by the 2-week self-quarantine guidelines from a different period combined with social distancing interventions. 
Figure 1. Epidemic curve of imported cases and local cases in South Korea. (A) Daily number of imported and local cases of COVID-19 in South Korea. (B) Daily number of imported and local cases in Seoul and Gyeonggi. Gray bars and green bars represent local cases and imported cases, respectively. WHO: World Health Organization.

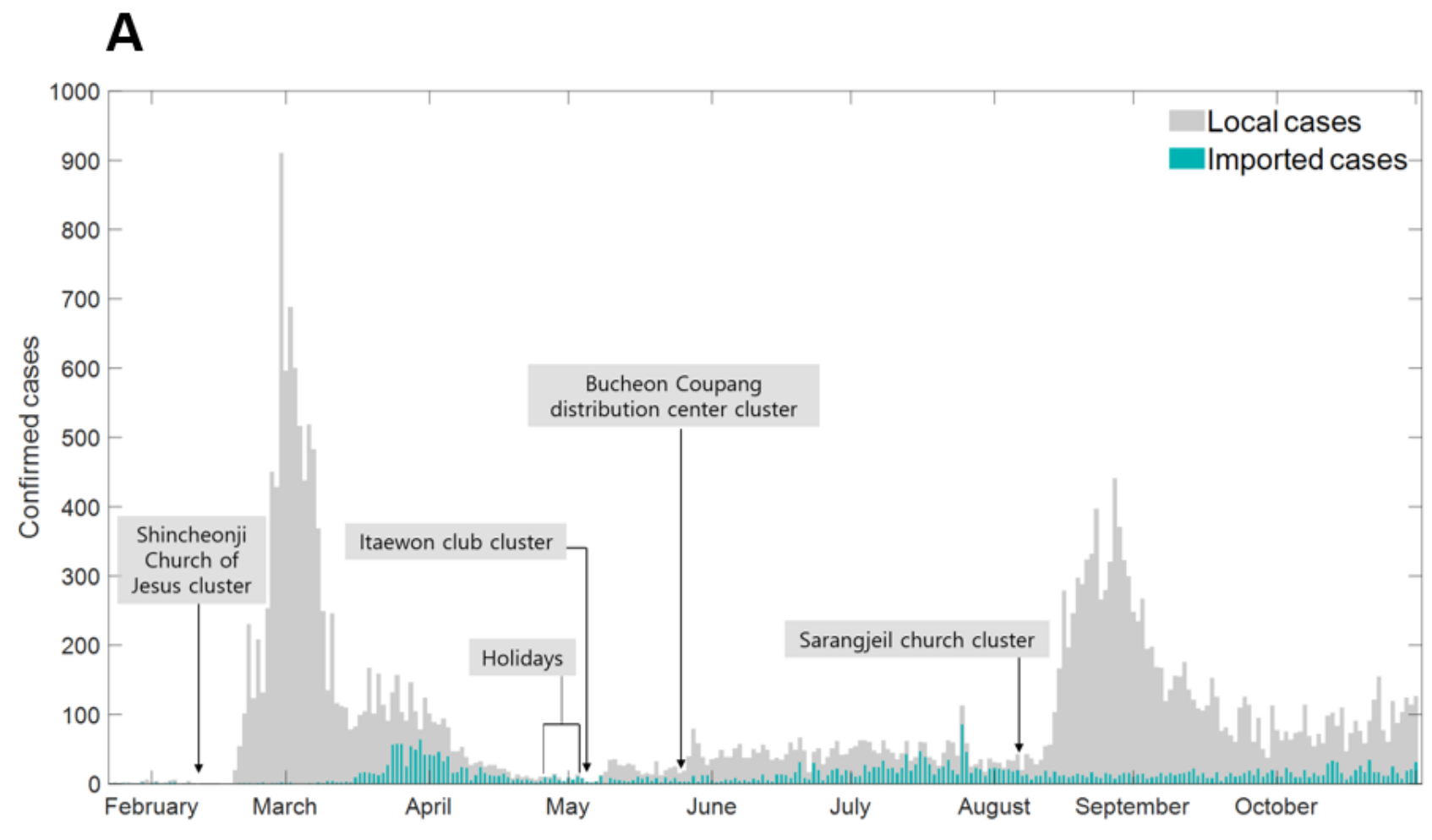

B

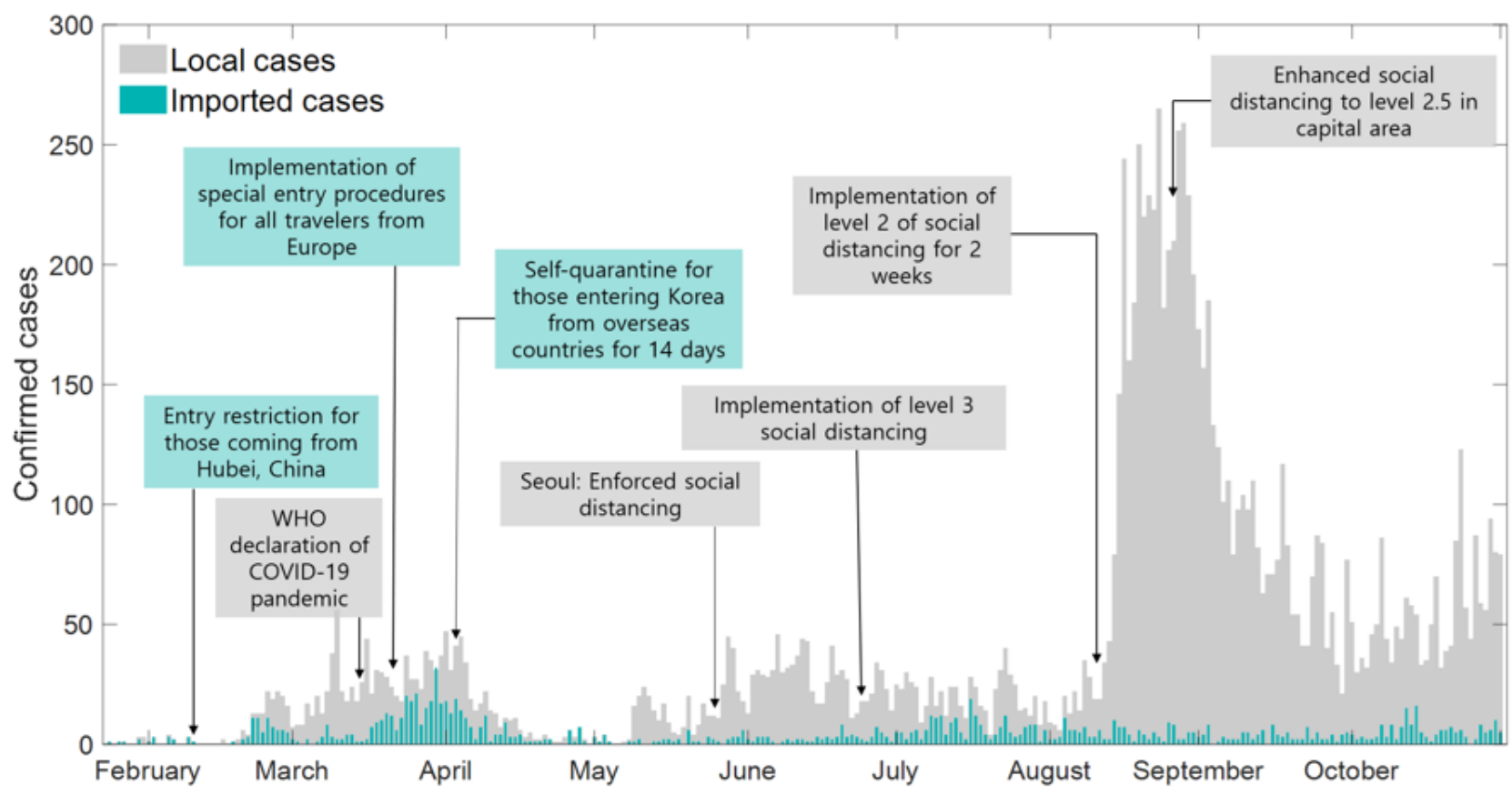

\section{Risk of Importation of COVID-19}

We aimed to calculate the country-specific importation risk of COVID-19 based on the number of international travelers, confirmed cases in the originating countries, and the population of the originating countries. The countries were grouped as Europe (the United Kingdom, Germany, and France); China and Asia except China; and North America (the United States and Canada). Country-specific importation risk is defined as a function of three factors: population, the number of confirmed cases of COVID-19, and passengers entering South Korea $[25,26]$. The risk of importation from a given country in a given month was derived as follows:

$$
\operatorname{Risk}_{c, t}=\frac{I_{c, t}}{\operatorname{pop}_{c}} T_{c, t}
$$

where $t$ is the month from January 2020 to October 2020 $(t=1,2, \ldots, 10)$ and $c$ is a group of countries $(c=\{$ China, Asia 
[except China], Europe, North America $)$ ). $I_{c, t}$ stands for the monthly confirmed cases of COVID-19 in a month $t$ and an originating country $c$. The population-adjusted density of infectious travelers was obtained by $I_{c, t}$ dividing its population pop $_{c}$ of country $c . T_{c, t}$ represents the number of passengers traveling from country $c$ in a month $t$. The normalized risk for country $c$ in month $t$ was as follows:

$$
\text { Normalized Risk } \mathrm{c}_{\mathrm{t}, \mathrm{t}}(\%)=\frac{\text { Risk }_{\mathrm{c}, \mathrm{t}}}{\operatorname{Max}\left(\operatorname{Risk}_{\mathrm{c}, \mathrm{t}}\right)} \times 100
$$

where $\operatorname{Max}\left(\mathrm{Risk}_{\mathrm{c}, \mathrm{t}}\right)$ indicates the maximum of the $\mathrm{Risk}_{\mathrm{c}, \mathrm{t}}$ for month $t$ and country $c$. Moreover, we obtained a correlation between the monthly number of passengers and cases of COVID-19. We calculated the monthly Pearson correlation coefficients between the number of passengers and the number of COVID-19 cases corresponding to different countries including Japan, Vietnam, the Philippines, the United States, China, Thailand, Taiwan, Malaysia, Singapore, Germany, France, Canada, and the United Kingdom. The Pearson correlation coefficients are higher than 0.7 from April 2020, indicating that the number of passengers had a linear relationship with the number of COVID-19 cases in 2020. Overall, this implied that prompt country-specific surveillance should be implemented for a more cautious screening process that may be applied to passengers from higher-risk countries. The high correlation was due to two major countries-China was the highest risk country in the early stages of the pandemic, while the United States was the highest risk country in the later stages of the pandemic.

\section{Estimation of Reproduction Numbers}

In this section, a renewal equation was employed to estimate the $R_{0}$. The $R_{0}$ is defined as the average number of susceptible individuals infected by a single primary case. Previous studies on COVID-19 estimated the $R_{0}$ to be 2-3 [26-28]. In this study, we have categorized the total cases into locally transmitted (local cases) and imported cases. The total incidence of COVID-19 at time $t$, denoted by $i(t)$, is the sum of local cases $\left(i_{L}(t)\right)$ and imported cases $\left(i_{o}(t)\right)$ - that is, $i(t)=i_{o}(t)+i_{L}(t)$. The renewal equation for the transmission dynamics of COVID-19 is defined as follows [29,30]:

$$
E\left(i_{L}(t)\right)=R_{0} \sum_{\tau=1}^{t}\left(i_{L}(t-\tau)+\alpha i_{o}(t-\tau)\right) f_{\tau}, 0 \leq \alpha \leq 1
$$

where $f \tau$ is the probability distribution of the serial interval in $\tau$, and $\alpha$ is the relative contribution of the imported cases to secondary disease transmission $(0 \leq \alpha \leq 1)$ [27,31]. A serial interval is the time interval from illness onset in a primary case (infector) to that in a second case (infectee) [28]. The serial interval was assumed according to the gamma distribution with a mean of 4.8 days (SD 2.3 days) [31,32]. The likelihood function, assuming that the daily counts follow a Poisson distribution, is defined as the following:
$L\left(R_{0} ; i_{L}(t), i_{o}(t)\right)=\sum_{t=1}^{t_{n}} \frac{e^{-E\left(i_{L}(t)\right)} E\left(i_{L(t)}\right)^{i_{L}(t)}}{i_{L}(t) !}$

where $t_{n}$ is the final time. We estimated the $R_{0}$ using the early confirmed cases from January 10 to February 25, 2020, using equations 3 and 4 . Here, $\alpha$ is the relative contribution of imported cases to secondary disease transmission [27,31]. In Seoul and Gyeonggi, there were secondary confirmed cases of importation until April 2020, and there were very few secondary confirmed cases due to stringent interventions such as screening and the self-quarantine policy from April to June 2020. In total, 48 secondary cases related to imported cases were reported until June 2020, and the parameter $\alpha$ was calculated based on the total confirmed cases by April and June 2020. As of April 2020, the value of $\alpha$ was $7.57 \%$, which was reduced to $3.63 \%$ in June 2020 .

The $R_{0}$ is relevant only in a largely susceptible population. Therefore, we also introduced the time-dependent reproduction number $R_{\mathrm{t}}$, calculated as the ratio of the number of new locally infected cases at time $t$ and all infected individuals at time $t$. The details of the $R_{\mathrm{t}}$ computation can be found elsewhere $[30,33]$. The effective reproduction number was estimated on sliding windows of width $W$ days, which was assumed to be a constant value over the time window ( $W$-day average of $R_{\mathrm{t}}$ ).

$$
R_{\mathrm{t}}=\frac{\sum_{s=t-W+1}^{t} i_{L}(s)}{\sum_{s=t-W+1}^{t} \sum_{u=1}^{t}\left(i_{L}(t-u)+\alpha i_{o}(t-u)\right) f_{u}}
$$

If $W=1$, the $R_{\mathrm{t}}$ is derived as follows:

$$
R_{\mathrm{t}}=\frac{i_{L}(t)}{\sum_{u=1}^{t}\left(i_{L}(t-u)+\alpha i_{o}(t-u)\right) f_{u}}
$$

\section{Ethical Considerations}

The data are presented in Table S1 in Multimedia Appendix 1. The data sets were fully anonymized and did not include any personally identifiable information. Thus, ethical approval was not required for the analysis.

\section{Results}

\section{Overview}

Relation between the number of passengers and imported cases was explored and the normalized country-specific risk was obtained. Among four groups of countries, China had a high risk of importation until February 2020. Afterward, North America showed a high risk of importation. The number of imported cases in Korea had a high correlation with the normalized risk, and the Spearman correlation coefficient was 0.82 . The $R_{0}$ was estimated at 1.87 (95\% CI 1.47-2.34) with the rate of $\alpha=0.07$ in Seoul and Gyeonggi. $R_{0}$ was varied according to $\alpha$ to be between 1.83 and 3.94 in South Korea. The $R_{\mathrm{t}}$ in South Korea and in Seoul and Gyeonggi were shown and interpreted along with the control interventions. 


\section{Imported and Local Cases of COVID-19 in South Korea}

Figure S1 in Multimedia Appendix 1 illustrates a summary of the epidemiological data on COVID-19 cases in South Korea. The top panels of Figure S1A in Multimedia Appendix 1 show the overall characteristics of the confirmed cases from February to October 2020. The leftmost panel shows the ratio of COVID-19 cases by region: $43 \%$ in the Seoul and Gyeonggi areas, 33\% in the Daegu and Gyeongbuk areas, and 24\% in the rest of South Korea. The second panel shows the ratio of imported cases $(14 \%)$ to local cases $(86 \%)$. The third panel shows the number of confirmed cases in Seoul and Gyeonggi and the ratio of imported cases $(10 \%)$ to local cases $(90 \%)$. The rightmost panel shows that $31 \%$ of imported cases were reported in Seoul and Gyeonggi. Seoul and Gyeonggi are the regions with the most inflow of foreigners in South Korea as they have major international airports (ie, Incheon International Airport and Gimpo International Airport).

Figure S1B in Multimedia Appendix 1 shows the monthly proportion of imported cases from five continents and the total proportion of imported cases (top left panel). A list of country-specific imported cases is given in Table $\mathrm{S} 1$ in Multimedia Appendix 1. The number of imported cases from China was large during January and April 2020, while that from North America and Europe increased until April 2020. However, the number of imported cases from Asia increased rapidly from May to October 2020; Asia (50.6\%), North America (28.1\%), and Europe $(17.8 \%)$ accounted for most of the cumulative imported cases.

\section{Relation Between the Number of Passengers and Imported Cases of COVID-19}

The importation risk implies that a country with more COVID-19 cases and more travelers entering South Korea has a higher risk of importation. Figure 2 shows the relationship between the number of passengers entering South Korea in 2020 and the monthly confirmed cases of COVID-19 between January and April in 2020. After February 2020, the number of Chinese passengers rapidly decreased due to the emerging outbreak of COVID-19 in China, as shown in Figures 2A and 2B. The number of confirmed cases and the number of passengers entering South Korea from the United States increased from March to October 2020, as shown in Figure S2 in Multimedia Appendix 1. This indicated that the number of passengers was dramatically reduced since the COVID-19 pandemic began, owing to travel bans and restrictions (see Table S2 in Multimedia Appendix 1). Next, the number of international travelers who arrived in South Korea in 2020 was compared with that in 2019 (Figure S3 in Multimedia Appendix 1). The number of country-specific confirmed cases and passengers per month from the top 13 countries from January to October 2020 are shown in Figures S4 and S5 in Multimedia Appendix 1, respectively. The number of cases in China was reduced dramatically from March 2020 (Figure S4A in Multimedia Appendix 1), while the number of cases in the United States, the United Kingdom, France, Germany, Canada, and Malaysia continued to increase until October 2020 (Figures S4H-M in Multimedia Appendix 1). However, the number of passengers was greatly reduced, regardless of country, as shown in Figure S5 in Multimedia Appendix 1. 
Figure 2. Relationship between the monthly number of passengers entering South Korea and COVID-19 cases at originating countries in (A) January, (B) February, (C) March, and (D) April 2020. The red stars represent particularly large numbers of COVID-19 cases (China and the United States).

A

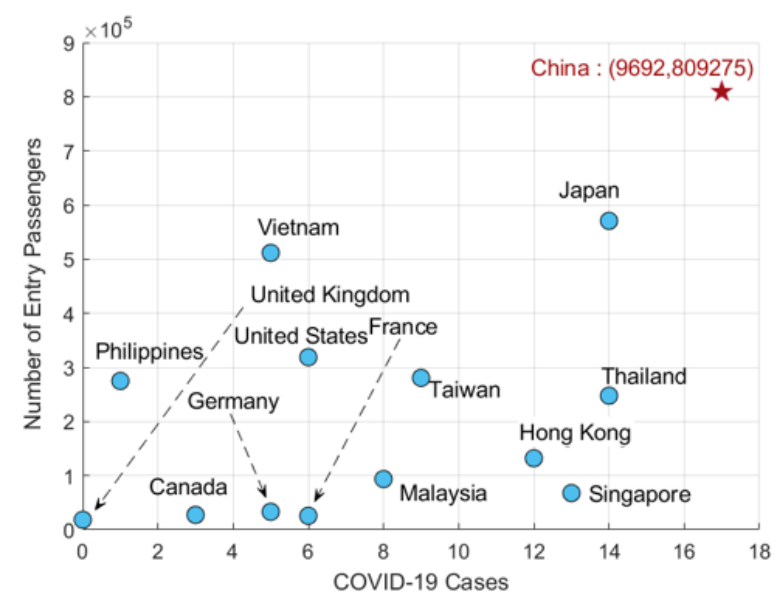

\section{C}

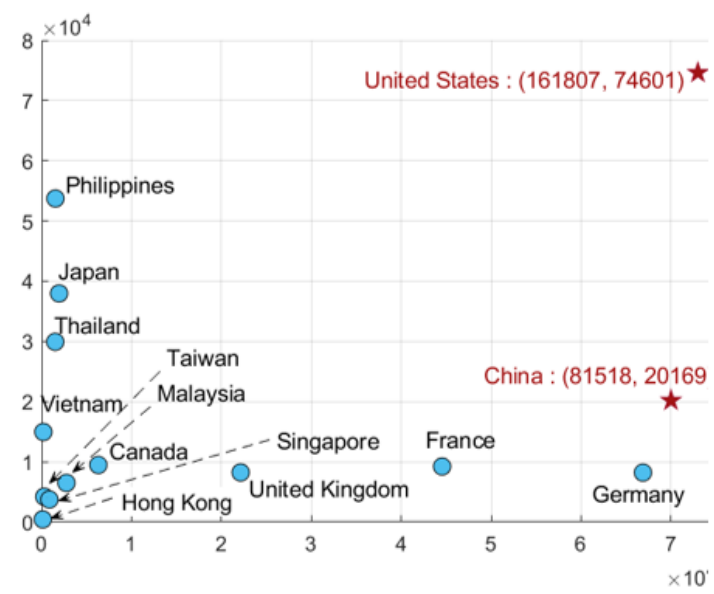

\section{Importation Risk of COVID-19}

We presented the risk of country-specific importation in Figure 3 and Table 1. Between January and February 2020, the risk of importation from China was the highest among the countries studied, while that from North America (the United States and
B

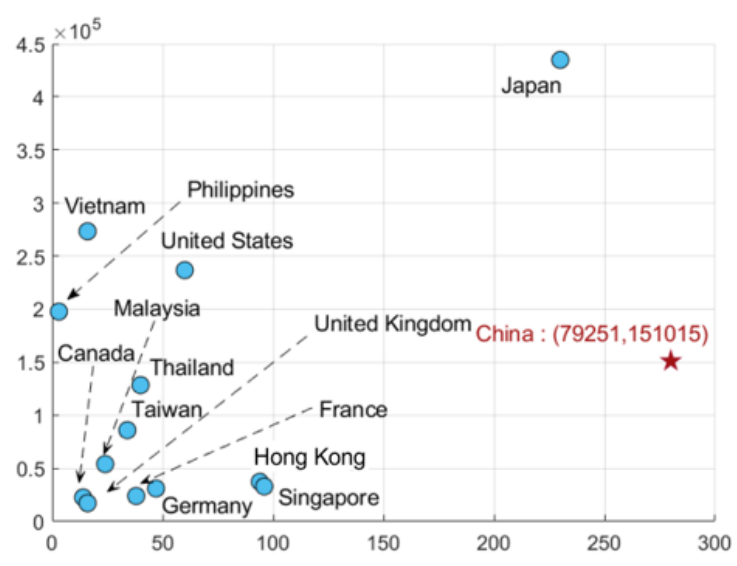

D

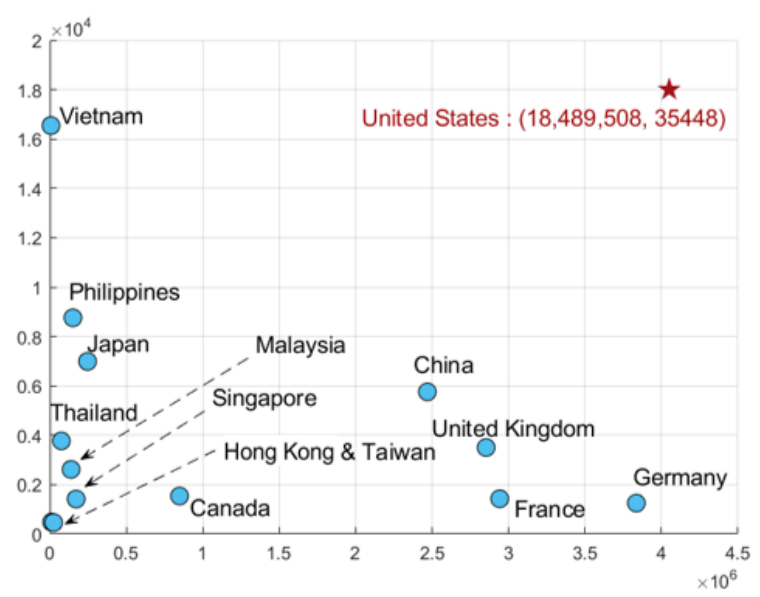

Canada) showed a significantly high risk of importation from April to October 2020. The number of imported cases was highly correlated with the normalized risk (the Spearman correlation coefficient and Kendall correlation coefficient were 0.82 and 0.64 , respectively). 
Figure 3. The country-specific risk of case importation from the top 13 countries to South Korea from January to October 2020.

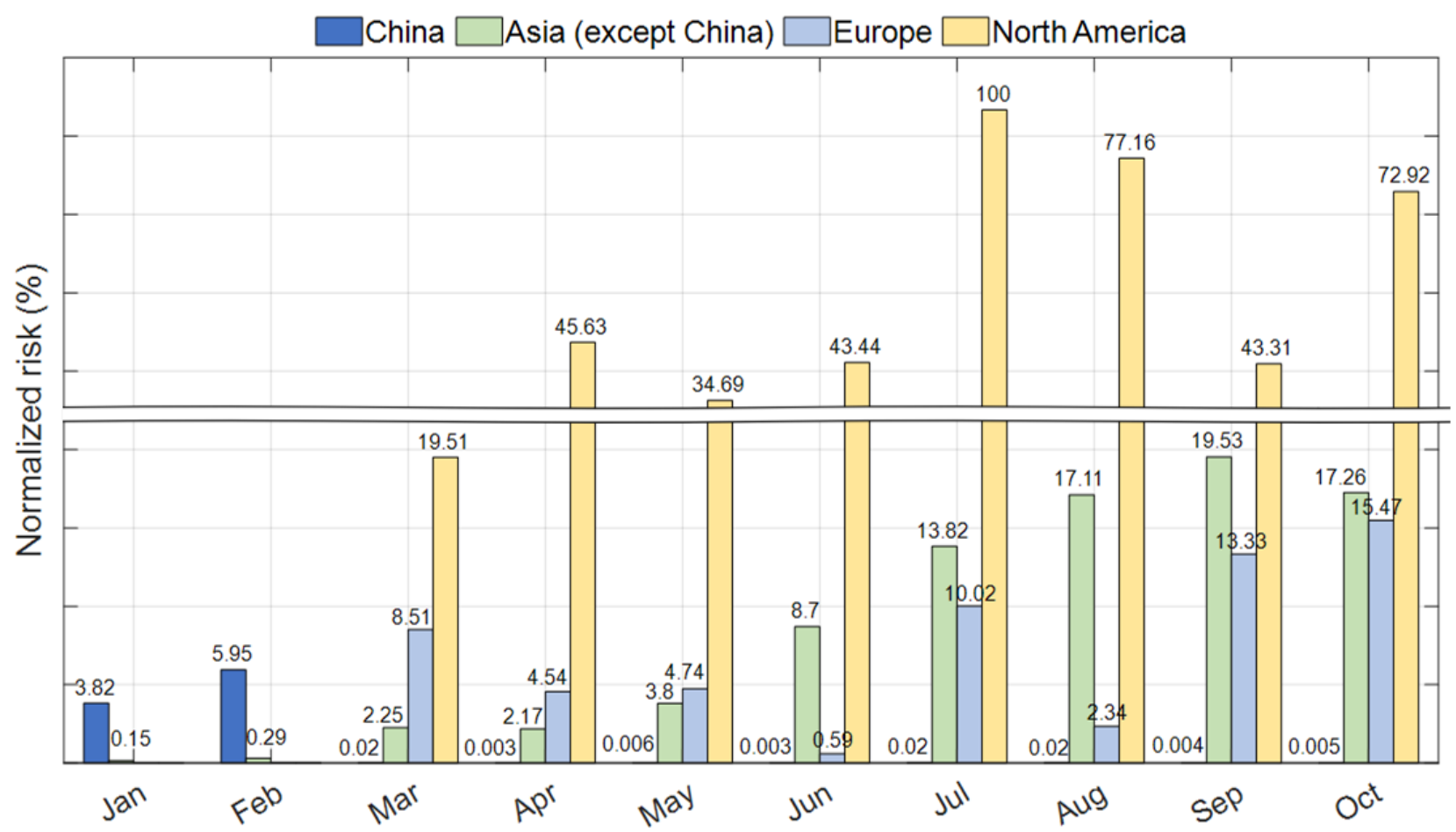


Table 1. Normalized risk of importation in South Korea by country using data on population, number of COVID-19 cases, and number of passengers from January to October in 2020.

\begin{tabular}{|c|c|c|c|}
\hline Country/region (population) and month & COVID-19 cases, $n$ & Passengers, $\mathrm{n}$ & Normalized risk of importation, $\%$ \\
\hline \multicolumn{4}{|l|}{ Europe $(214,921,407)$} \\
\hline January & 11 & 77,183 & 0.002 \\
\hline February & 115 & 72,133 & 0.02 \\
\hline March & 141,116 & 25,656 & 8.51 \\
\hline April & 453,720 & 6182 & 4.54 \\
\hline May & 584,312 & 3450 & 4.74 \\
\hline June & 634,734 & 4963 & 0.59 \\
\hline July & 684,781 & 6224 & 10.02 \\
\hline August & 833,071 & 6701 & 2.34 \\
\hline September & $1,233,958$ & 4595 & 13.33 \\
\hline October & $2,715,743$ & 4441 & 15.47 \\
\hline \multicolumn{4}{|l|}{ Asia, except China $(3,032,800,000)$} \\
\hline January & 168 & $5,535,607$ & 0.15 \\
\hline February & 1254 & $1,397,128$ & 0.29 \\
\hline March & 70,717 & 190,649 & 2.25 \\
\hline April & 224,609 & 57,968 & 2.17 \\
\hline May & 558,836 & 40,838 & 3.8 \\
\hline June & $1,105,224$ & 47,219 & 8.7 \\
\hline July & $1,786,777$ & 46,420 & 13.82 \\
\hline August & $2,709,219$ & 37,908 & 17.11 \\
\hline September & $3,410,902$ & 34,362 & 19.53 \\
\hline October & $3,009,642$ & 34,419 & 17.26 \\
\hline \multicolumn{4}{|l|}{ China $(1,399,620,000)$} \\
\hline January & 9701 & $1,089,779$ & 3.82 \\
\hline February & 79,285 & 236,911 & 5.95 \\
\hline March & 81,824 & 24,381 & 0.02 \\
\hline April & 83,287 & 6242 & 0.003 \\
\hline May & 85,012 & 9479 & 0.006 \\
\hline June & 85,674 & 11,120 & 0.003 \\
\hline July & 88,423 & 15,323 & 0.02 \\
\hline August & 90,839 & 19,579 & 0.02 \\
\hline September & 91,480 & 18,690 & 0.004 \\
\hline October & 92,402 & 16,193 & 0.005 \\
\hline \multicolumn{4}{|l|}{ North America $(365,968,433)$} \\
\hline January & 9 & 346,090 & 0.004 \\
\hline February & 74 & 259,247 & 0.02 \\
\hline March & 168,124 & 84,074 & 19.51 \\
\hline April & $1,061,615$ & 36,987 & 45.63 \\
\hline May & $1,805,819$ & 33,757 & 34.69 \\
\hline June & $2,640,886$ & 37,676 & 43.44 \\
\hline July & $4,504,036$ & 38,869 & 100 \\
\hline
\end{tabular}




\begin{tabular}{llll}
\hline Country/region (population) and month & COVID-19 cases, $\mathrm{n}$ & Passengers, $\mathrm{n}$ & Normalized risk of importation, \% \\
\hline August & $5,982,879$ & 37,783 & 77.16 \\
September & $7,110,608$ & 27,809 & 43.31 \\
October & $8,989,268$ & 28,109 & 72.92 \\
\hline
\end{tabular}

Figure 4 showed the results of regression analysis between the country-specific risk and the number of imported cases according to the four different countries/regions. The estimated values using the regression analysis are summarized in Table S3 in Multimedia Appendix 1. All countries had a positive relationship between imported cases and the risk of importation because the estimates of the slopes were positive. The linear regression models were well fitted, especially for China $\left(R^{2}=0.78\right)$. Asia (except China) was the most affected region with respect to the risk of importation. It is clear that imported cases entering from Asia (except China) can increase much more if the risk importation of Asia (except China) is elevated.

Figure 4. Regression analysis between the imported cases in South Korea from (A) North America, (B) Asia (except China), (C) China, and (D) Europe, and normalized risk $(\%)$. The dots indicate the number of imported cases in South Korea and solid lines represent the fitted linear regression. NRisk: normalized risk.
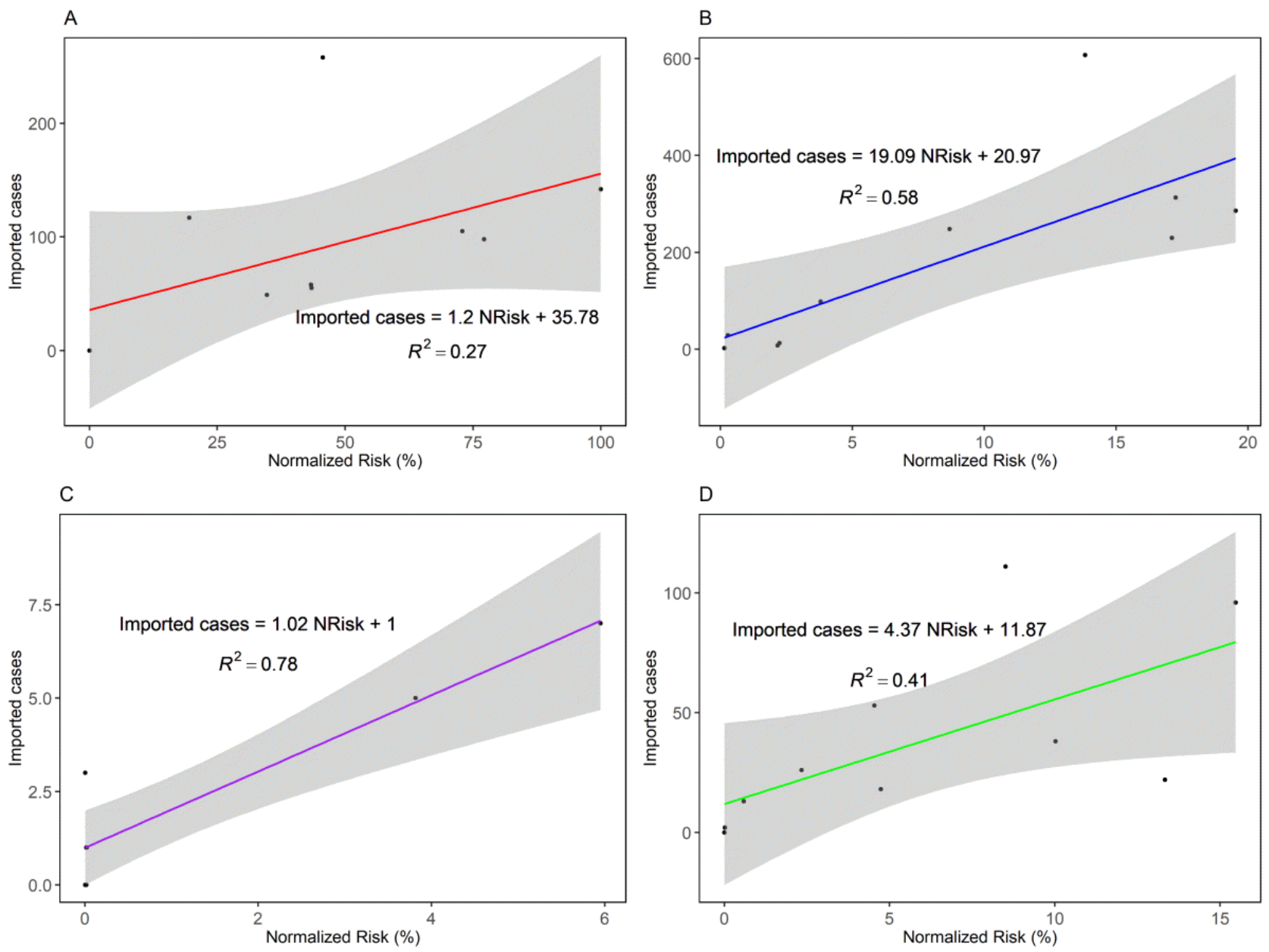

\section{Reproduction Number}

We varied $\alpha$ from 0 to 1 and estimated the $R_{0}$ for the early COVID-19 outbreak in Seoul and Gyeonggi based on COVID-19 confirmed cases from January 10 to February 25, 2020, while the $R_{0}$ in South Korea was based on COVID-19 confirmed cases from February 1 to February 19 (Table 2). Figure 5 shows the comparison between the COVID-19 data

and estimated cases (Figure 5A) and cumulative local cases (Figure 5B). The corrected Akaike information criterion was calculated at 159.08 and the Bayesian information criterion was 160.84. Table 2 illustrates the estimation of $R_{0}$ with varying $\alpha$. The estimated $R_{0}$ was 1.87 (95\% CI 1.47-2.34) with $\alpha=0.07$ and 1.49 (95\% CI 1.17-1.87) with $\alpha=1.0$. This indicated that the value of $R_{0}$ decreased with increasing $\alpha$ since there was no secondary infection from imported cases $(\alpha=1)$. 
Figure 5. Comparison between estimated cases and observed cases of COVID-19 in Seoul and Gyeonggi using $R_{0}$ when $\alpha=0.07$. (A) Daily local cases in Seoul and Gyeonggi. (B) Cumulative local cases in Seoul and Gyeonggi. The red bar shows the estimated cases, while the blue bar shows the observed COVID-19 cases in the Seoul and Gyeonggi regions.
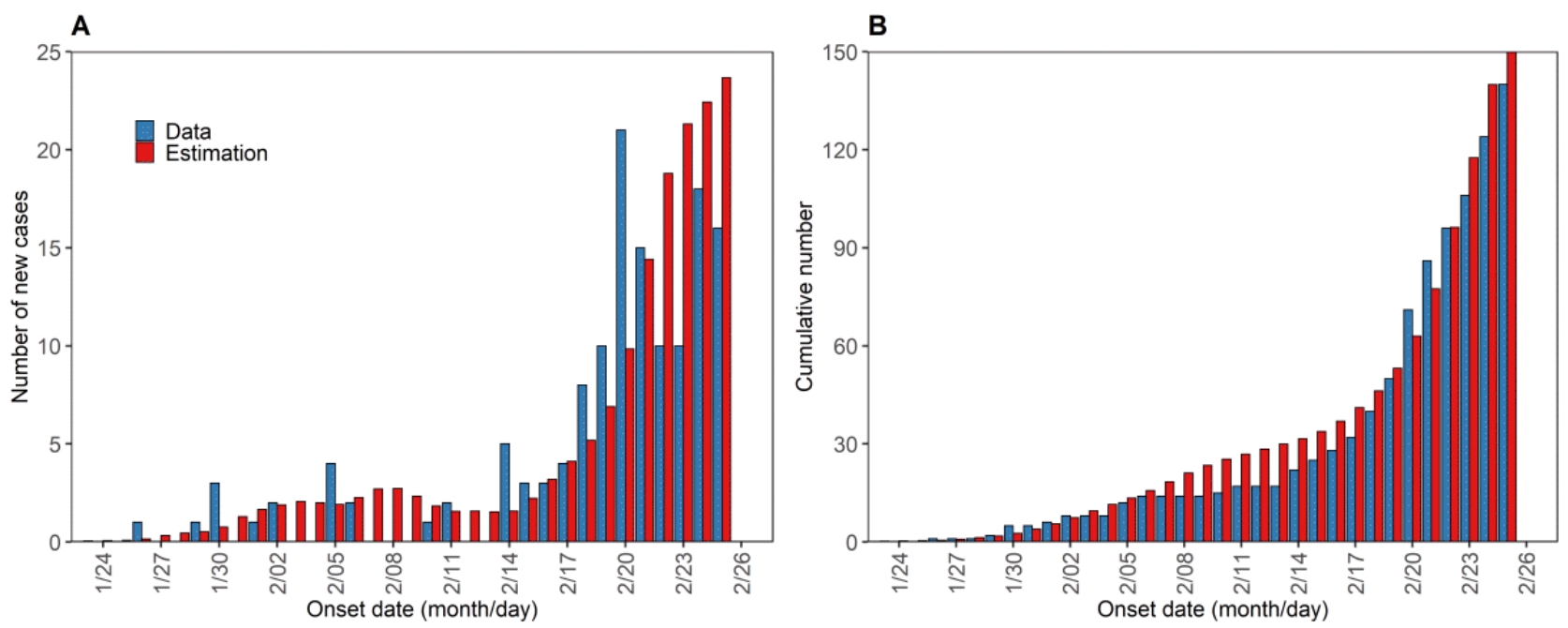

Table 2. Estimation of $\mathrm{R}_{0}$ by $\alpha$.

\begin{tabular}{lll}
\hline$\alpha$ value & $R_{0}$ of Korea $(95 \% \mathrm{CI})^{\mathrm{a}}$ & $R_{0}$ of Seoul and Gyeonggi $(95 \% \mathrm{CI})^{\mathrm{a}}$ \\
\hline 0.00 & $3.94(2.18-6.04)$ & $1.89(1.49-2.38)$ \\
0.07 & $3.76(2.11-5.75)$ & $1.87(1.47-2.34)$ \\
0.10 & $3.63(2.05-5.58)$ & $1.85(1.46-2.33)$ \\
0.30 & $2.98(1.71-4.66)$ & $1.76(1.38-2.21)$ \\
0.50 & $2.53(1.47-4.00)$ & $1.67(1.31-2.10)$ \\
0.70 & $2.19(1.28-3.50)$ & $1.59(1.25-2.00)$ \\
1.00 & $1.83(1.08-2.94)$ & $1.49(1.17-1.87)$ \\
\hline
\end{tabular}

${ }^{\mathrm{a}} 95 \%$ CI was calculated from profile likelihood [34].

The $R_{\mathrm{t}}$ was calculated for $\alpha=0.07$ and the daily epidemic curves of imported (green) and local (gray) cases and the $R_{\mathrm{t}}$ values (blue curve) in the Seoul and Gyeonggi regions are shown in Figure 6. On March 11, 2020, when the WHO declared a pandemic situation, the $R_{\mathrm{t}}$ value fell below 1 . At the beginning of the holiday season in early May 2020, the value again increased rapidly. In addition, there was a large outbreak in
August and September 2020 due to a public gathering from all over South Korea on August 15, 2020. We conducted the sensitivity analysis for $R_{\mathrm{t}}$ according to the different time windows and $\alpha$ values (Figures S6A and S6B in Multimedia Appendix 1). Additionally, the $R_{\mathrm{t}}$ in South Korea from April to October 2020 is shown in Figures S6C and S6D in Multimedia Appendix 1. 
Figure 6. Local and imported cases and $\mathrm{R}_{\mathrm{t}}$ in Seoul and Gyeonggi. The daily epidemic curves of imported (green) and local (gray) cases are shown. The blue curve shows the value of $R_{t}$ when $\alpha=0.07$ and the black horizontal line denotes $R_{t}=1$.

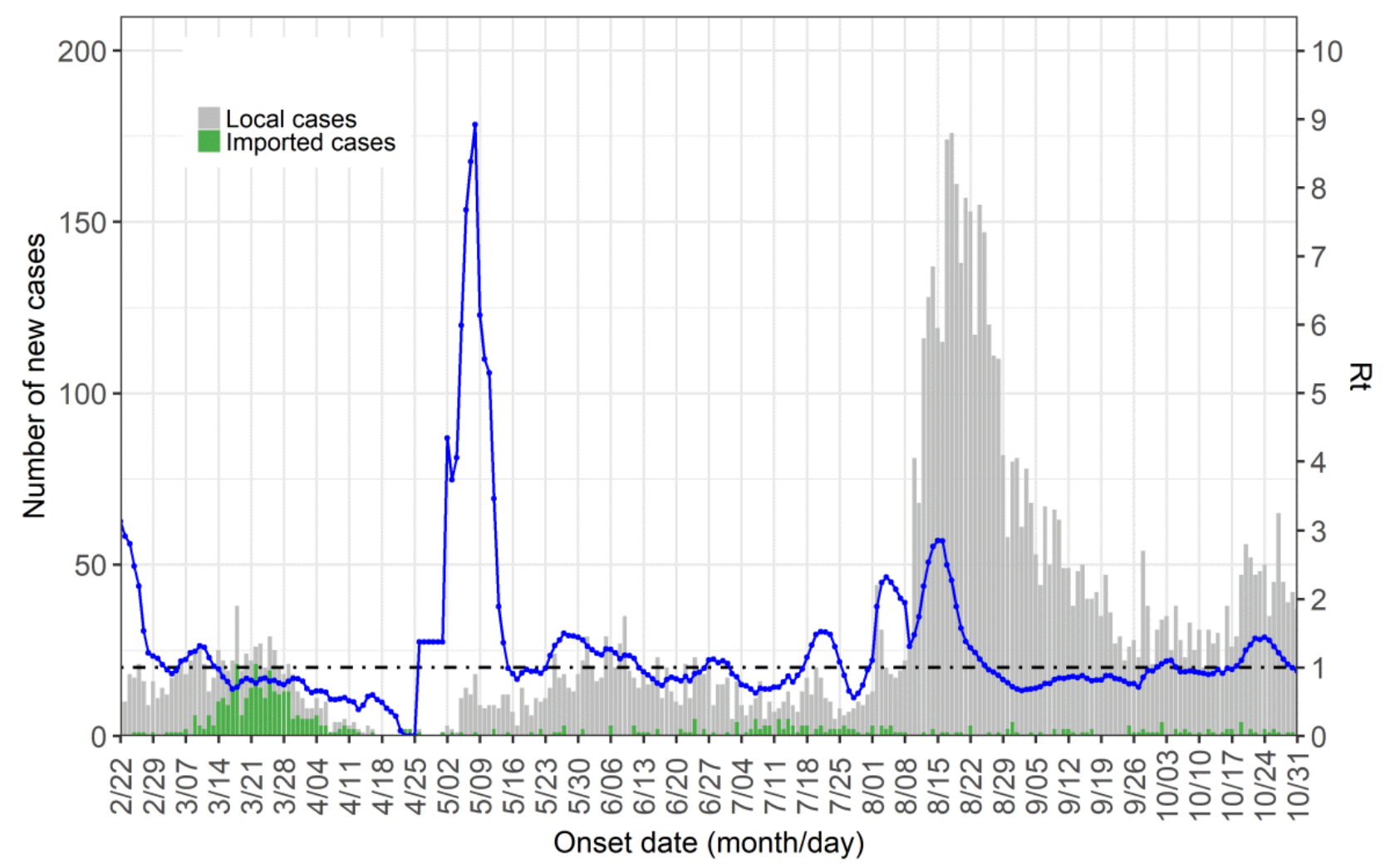

\section{Discussion}

\section{Principal Findings}

In this study, we analyzed country-specific epidemiological data and data on passengers entering South Korea from January to October 2020. First, the correlation between the number of passengers and COVID-19 cases by country was calculated. A country with more confirmed cases showed a higher risk of importation. Second, the country-specific risk was highly correlated with the number of imported cases by country (Spearman correlation coefficient $=0.82$ ); China had the highest importation risk of COVID-19 in the early stages of the pandemic (January and February 2020), while North America (United States and Canada) showed the high importation risk from April to October 2020. Third, for the early stages of the COVID-19 pandemic, the $R_{0}$ was estimated at 1.87 (95\% CI 1.47-2.34), which was similar to the $R_{0}$ of COVID-19 of approximately $2-3$ in Wuhan, China $[28,35,36]$. Finally, we estimated the $R_{\mathrm{t}}$ by employing the renewal equation, accounting for the effects of control interventions.

Mainland China and South Korea experienced a steep rise in the number of COVID-19 confirmed cases in the early stages of the COVID-19 pandemic [3,32]. It appears that the two governments' respective reactions to the novel virus resulted in a successful reduction in infection rates; however, the cost burden that the two countries had to bear was quite different. China implemented a lockdown in Hubei province and strict border control measures against higher-risk countries [37,38].
In China, active measures driven by the central government to retard the progress of epidemic diseases appear to be effective in impeding the spread of COVID-19; however, Chinese people had to pay burdensome costs during the initial outbreak of COVID-19 [39]. South Korea used strict social distancing measures and self-quarantine without restricting borders. However, South Korea expanded the volume of testing and promptly traced the contacts of confirmed cases $[32,40]$.

There were potential risk factors that could have led to a larger outbreak of COVID-19 in South Korea. First, negative serial intervals indicated presymptomatic transmissions, highlighting the potential risk of transmission from asymptomatic cases. In South Korea, $12.7 \%$ of serial intervals were negative (199 pairs among 1567 symptomatic pairs), which could lead to large outbreaks as secondary transmission before the appearance of symptoms cannot be prevented [40,41]. Second, the $R_{0}$ was estimated at 1.49 in Seoul and Gyeonggi, indicating that an epidemic might be possible. Third, the number of imported cases increased substantially from April 2020, although passenger volume has been rapidly decreasing due to the increase in COVID-19 cases. However, a large outbreak of COVID-19 caused by imported cases did not occur because of the policy of testing passengers arriving from other countries and isolating them for a minimum of 2 weeks; this policy was implemented on April 1, 2020, and reduced the risk of the spread of COVID-19.

This study has several limitations. First, this study relied on confirmed cases in South Korea. However, there were a 
substantial number of asymptomatic infections as $12.5 \%$ of serial intervals were negative [41], which represents presymptomatic transmission $[32,40]$. Thus, we did not consider secondary transmission caused by imported and local cases. Second, we analyzed the impact of imported cases on the local transmission of COVID-19 and found that the impact of imported cases had decreased since the strict implementation of airport screening and quarantine measures from April 2020 [24,42] (Table S2 in Multimedia Appendix 1). Therefore, the potential risk of infection from imported cases was regarded as a less important factor. However, the reason for the small outbreaks resulting from imported cases was due to strengthened screening inspection and self-quarantine measures for those entering South Korea, which were implemented on April 1, 2020. This means that secondary transmission by imported cases can play a critical role in COVID-19 transmission. Finally, the risk was estimated by month as monthly passenger volume data were available. If daily data were given, the risk by country could be computed daily or weekly. However, we observed a significantly different risk of importation of COVID-19 from overseas countries.

Despite these limitations, we investigated the risk of importation of COVID-19 using country-specific epidemiological data and passenger volume. By combining social distancing, screening, and self-quarantine for all travelers entering South Korea, the mitigation of COVID-19 transmission caused by imported cases in South Korea was highly successful. These efforts-accompanied by identification of the source of infection and strengthened quarantine measures for travelers from overseas countries - should be continued. Therefore, it is urgent to assess the risk of importation and maintain an effective surveillance system for COVID-19 in South Korea.

Strict control interventions were implemented to prevent the spread of COVID-19 in South Korea since the first case was confirmed in the country on January 20, 2020. The COVID-19 outbreak in South Korea has been successfully suppressed without strict lockdowns. First, the Korean government has constructed a rapid testing and diagnosis system [40,43]. Previous studies have shown that most cases have been confirmed within a week of illness onset [24,43]. Moreover, drive-through screening centers were initiated on February 23, 2020, in Daegu, South Korea [44]. This system contributed to the rapid diagnosis and further testing of suspected cases. The entire drive-through testing procedure takes about 10 minutes, and it is helpful for diagnosing infections early in cases with mild symptoms or asymptomatic cases. Second, the widespread epidemiological investigation of contact tracing was conducted in infected as well as suspected cases [40]. Social distancing strategies and mask wearing have been recommended since February 2020. Social distancing has been found to mitigate the spread of COVID-19 cases [40,45,46]. Third, the Korean government introduced a "special entry procedure," which was applied to all passengers from mainland China from February 4, 2020, to control imported cases. Subsequently, all passengers from overseas countries were quarantined for 14 days after April 1, 2020. Combined control interventions, including social distancing efforts, appear to have succeeded in preventing the spread of COVID-19 in South Korea.

Since the severity of COVID-19 outbreaks and health policies differ across countries, a country-specific surveillance system would be more efficient than a uniform screening and surveillance policy for every country. Another notable feature of South Korean border control is that the number of international travel hubs is limited, and passenger traffic can be effectively monitored. This, in turn, helps in diagnosing and tracing imported cases without imposing a strict lockdown. It is important to estimate the country-specific risk of importation by identifying high-risk countries to prevent recurrent outbreaks due to importation of cases. It would be helpful to access a finer level of information to estimate the effective reproduction number as the risk indicator of importation and local transmission. Therefore, our framework can also be applied to countries that have similar immigration policies. Furthermore, a risk assessment of imported cases between neighboring countries that do not implement border control (eg, the Schengen zone or Central America-4 Free Mobility Agreement) might be challenging.

\section{Conclusions}

Data on international passengers entering South Korea, the severity of the COVID-19 outbreak in originating countries, and country-specific imported cases were analyzed to compute the risk of importation of COVID-19 into South Korea. China was a high-risk country for importation in the early stages of the pandemic until March 2020, while the United States and Canada showed a high risk of importation after April 2020. Moreover, statistical model accounting was employed to estimate the $R_{0}$ and $R_{\mathrm{t}}$ using epidemiological data on imported and locally transmitted cases. Our results highlighted that rapid diagnosis and prompt implementation of case isolation and quarantine were effective in preventing secondary infections caused by imported cases through the continuous inflow of passengers traveling from high-risk countries. Therefore, multiple mitigation interventions (social distancing, a rapid diagnosis system, and movement restriction) should be implemented to reduce the spread of local and imported cases in South Korea.

\section{Acknowledgments}

HL received a grant from the National Institute for Mathematical Sciences (NIMS) funded by the Korean Government (NIMS-B21910000). This study was supported by the Samsung Science \& Technology Foundation under Project Number SSTF-BA2002-02.

\section{Conflicts of Interest}

None declared. 


\section{Multimedia Appendix 1}

Supplementary data.

[DOCX File, 1004 KB-Multimedia Appendix 1]

\section{References}

1. Park SE. Epidemiology, Virology, and Clinical Features of Severe Acute Respiratory Syndrome Coronavirus 2 (SARS-CoV-2; Coronavirus Disease-19). Pediatr Infect Vaccine 2020;27(1):1. [doi: 10.14776/piv.2020.27.e9]

2. Gandhi RT, Lynch JB, del Rio C. Mild or Moderate Covid-19. N Engl J Med 2020 Oct 29;383(18):1757-1766. [doi: 10.1056/nejmcp2009249]

3. Coronavirus disease (COVID-19) pandemic. World Health Organization. URL: https://www.who.int/emergencies/diseases/ novel-coronavirus-2019 [accessed 2021-05-14]

4. Lloyd-Smith JO, Schreiber SJ, Kopp PE, Getz WM. Superspreading and the effect of individual variation on disease emergence. Nature 2005 Nov 17;438(7066):355-359 [FREE Full text] [doi: 10.1038/nature04153] [Medline: 16292310]

5. Cauchemez S, Nouvellet P, Cori A, Jombart T, Garske T, Clapham H, et al. Unraveling the drivers of MERS-CoV transmission. Proc Natl Acad Sci U S A 2016 Aug 09;113(32):9081-9086 [FREE Full text] [doi: 10.1073/pnas.1519235113] [Medline: 27457935]

6. Liu J, Xie W, Wang Y, Xiong Y, Chen S, Han J, et al. A comparative overview of COVID-19, MERS and SARS: Review article. Int J Surg 2020 Sep;81:1-8 [FREE Full text] [doi: 10.1016/j.ijsu.2020.07.032] [Medline: 32730205]

7. Kirby T. New variant of SARS-CoV-2 in UK causes surge of COVID-19. The Lancet Respiratory Medicine 2021 Feb;9(2):e20-e21. [doi: 10.1016/s2213-2600(21)00005-9]

8. Brockmann D, Helbing D. The hidden geometry of complex, network-driven contagion phenomena. Science 2013 Dec 13;342(6164):1337-1342 [FREE Full text] [doi: 10.1126/science.1245200] [Medline: 24337289]

9. Poletto C, Boëlle PY, Colizza V. Risk of MERS importation and onward transmission: a systematic review and analysis of cases reported to WHO. BMC Infect Dis 2016 Aug 25;16(1):448 [FREE Full text] [doi: 10.1186/s12879-016-1787-5] [Medline: 27562369]

10. Pullano G, Pinotti F, Valdano E. Novel coronavirus (2019-nCoV) early-stage importation risk to Europe, January 2020. Euro Surveill 2020:25. [doi: 10.2807/1560-7917.es.2020.25.4.2000057]

11. Haider N, Yavlinsky A, Simons D, Osman AY, Ntoumi F, Zumla A, et al. Passengers' destinations from China: low risk of Novel Coronavirus (2019-nCoV) transmission into Africa and South America. Epidemiol Infect 2020 Feb 26;148:e41. [doi: 10.1017/s0950268820000424]

12. Chinazzi M, Davis JT, Ajelli M, Gioannini C, Litvinova M, Merler S, et al. The effect of travel restrictions on the spread of the 2019 novel coronavirus (COVID-19) outbreak. Science 2020 Apr 24;368(6489):395-400 [FREE Full text] [doi: 10.1126/science.aba9757] [Medline: 32144116]

13. Wells CR, Sah P, Moghadas SM, Pandey A, Shoukat A, Wang Y, et al. Impact of international travel and border control measures on the global spread of the novel 2019 coronavirus outbreak. Proc Natl Acad Sci USA 2020 Mar 31;117(13):7504-7509 [FREE Full text] [doi: 10.1073/pnas.2002616117] [Medline: 32170017]

14. Zhang L, Yang H, Wang K, Zhan Y, Bian L. Measuring imported case risk of COVID-19 from inbound international flights --- A case study on China. J Air Transp Manag 2020 Oct;89:101918 [FREE Full text] [doi: 10.1016/j.jairtraman.2020.101918] [Medline: 32904487$]$

15. Han Y, Liu Y, Zhou L, Chen E, Liu P, Pan X, et al. Epidemiological Assessment of Imported Coronavirus Disease 2019 (COVID-19) Cases in the Most Affected City Outside of Hubei Province, Wenzhou, China. JAMA Netw Open 2020 Apr 01;3(4):e206785 [FREE Full text] [doi: 10.1001/jamanetworkopen.2020.6785] [Medline: $\underline{32324236]}$

16. Liu J, Chen T, Hwang S. Analysis of Imported Cases of COVID-19 in Taiwan: A Nationwide Study. Int J Environ Res Public Health 2020 May 09;17(9):3311 [FREE Full text] [doi: 10.3390/ijerph17093311] [Medline: $\underline{32397515]}$

17. Nakamura H, Managi S. Airport risk of importation and exportation of the COVID-19 pandemic. Transp Policy (Oxf) 2020 Sep;96:40-47 [FREE Full text] [doi: 10.1016/j.tranpol.2020.06.018] [Medline: 32834679]

18. 2020 COVID-19 outbreak in the Republic of Korea. Korea Centers for Disease Control and Prevention. URL: http://ncov. mohw.go.kr [accessed 2020-11-02]

19. Corona 19 response. Seoul Metropolitan Government. URL: http://ebook.seoul.go.kr/library/list content. php?class=46\&order=date [accessed 2020-11-02]

20. Incheon International Airport Corporation in the Republic of Korea. URL: https://www.airport.kr/co/ko/index.do [accessed 2020-11-20]

21. Situation reports: Coronavirus disease (COVID-19) Weekly Epidemiological Update and Weekly Operational Update. World Health Organization. URL: https://www.who.int/emergencies/diseases/novel-coronavirus-2019/situation-reports/ [accessed 2021-05-14]

22. List of countries and dependencies by population. Wikipedia. URL: https://en.wikipedia.org/wiki/ List of countries and dependencies by population [accessed 2020-03-03] 
23. Bae TW, Kwon KK, Kim KH. Mass Infection Analysis of COVID-19 Using the SEIRD Model in Daegu-Gyeongbuk of Korea from April to May, 2020. J Korean Med Sci 2020 Aug 31;35(34):e317 [FREE Full text] [doi: 10.3346/jkms.2020.35.e317] [Medline: $\underline{32864913}$ ]

24. COVID-19 National Emergency Response Center, Epidemiology and Case Management Team, Korea Centers for Disease Control and Prevention. Coronavirus Disease-19: The First 7,755 Cases in the Republic of Korea. Osong Public Health Res Perspect 2020 Apr;11(2):85-90 [FREE Full text] [doi: 10.24171/j.phrp.2020.11.2.05] [Medline: 32257774]

25. Fauver JR, Petrone ME, Hodcroft EB, Shioda K, Ehrlich HY, Watts AG, et al. Coast-to-Coast Spread of SARS-CoV-2 during the Early Epidemic in the United States. Cell 2020 May 28;181(5):990-996.e5 [FREE Full text] [doi: 10.1016/j.cell.2020.04.021] [Medline: $\underline{\text { 32386545] }}$

26. Haider N, Yavlinsky A, Simons D, Osman AY, Ntoumi F, Zumla A, et al. Passengers' destinations from China: low risk of Novel Coronavirus (2019-nCoV) transmission into Africa and South America. Epidemiol Infect 2020 Feb 26;148:1. [doi: $10.1017 / \mathrm{s} 0950268820000424]$

27. Tariq A, Lee Y, Roosa K, Blumberg S, Yan P, Ma S, et al. Real-time monitoring the transmission potential of COVID-19 in Singapore, March 2020. BMC Med 2020 Jun 03;18(1):166 [FREE Full text] [doi: 10.1186/s12916-020-01615-9] [Medline: 32493466]

28. Zhao S, Gao D, Zhuang Z, Chong MKC, Cai Y, Ran J, et al. Estimating the Serial Interval of the Novel Coronavirus Disease (COVID-19): A Statistical Analysis Using the Public Data in Hong Kong From January 16 to February 15, 2020. Front Phys 2020 Sep 17;8:8. [doi: 10.3389/fphy.2020.00347]

29. Thompson RN, Stockwin JE, van Gaalen RD, Polonsky JA, Kamvar ZN, Demarsh PA, et al. Improved inference of time-varying reproduction numbers during infectious disease outbreaks. Epidemics 2019 Dec;29:100356 [FREE Full text] [doi: 10.1016/j.epidem.2019.100356] [Medline: $\underline{31624039]}$

30. Chan YD, Flasche S, Lam TT, Leung MJ, Wong M, Lam H, et al. Transmission dynamics, serial interval and epidemiology of COVID-19 diseases in Hong Kong under different control measures. Wellcome Open Res 2020 Nov 9;5:91. [doi: 10.12688/wellcomeopenres.15896.2]

31. Shim E, Tariq A, Choi W, Lee Y, Chowell G. Transmission potential and severity of COVID-19 in South Korea. Int J Infect Dis 2020 Apr;93:339-344 [FREE Full text] [doi: 10.1016/j.ijid.2020.03.031] [Medline: $\underline{32198088}$ ]

32. Nishiura H, Linton NM, Akhmetzhanov AR. Serial interval of novel coronavirus (COVID-19) infections. Int J Infect Dis 2020 Apr;93:284-286 [FREE Full text] [doi: 10.1016/j.ijid.2020.02.060] [Medline: 32145466]

33. Dalziel BD, Lau MSY, Tiffany A, McClelland A, Zelner J, Bliss JR, et al. Unreported cases in the 2014-2016 Ebola epidemic: Spatiotemporal variation, and implications for estimating transmission. PLoS Negl Trop Dis 2018 Jan 22;12(1):e0006161 [FREE Full text] [doi: 10.1371/journal.pntd.0006161] [Medline: 29357363]

34. Cole SR, Chu H, Greenland S. Maximum Likelihood, Profile Likelihood, and Penalized Likelihood: A Primer. American Journal of Epidemiology 2013 Oct 29;179(2):252-260. [doi: 10.1093/aje/kwt245]

35. Imai N, Dorigatti I, Cori A, Donnelly C, Riley S, Ferguson NM. Report 2 - Estimating the potential total number of novel Coronavirus (2019-nCoV) cases in Wuhan City, China. MRC Centre for Global Infectious Disease Analysis. 2020 Jan 22. URL: https://www.imperial.ac.uk/mrc-global-infectious-disease-analysis/covid-19/report-2-update-case-estimates-covid-19/ [accessed 2021-05-14]

36. Zhao S, Lin Q, Ran J, Musa SS, Yang G, Wang W, et al. Preliminary estimation of the basic reproduction number of novel coronavirus (2019-nCoV) in China, from 2019 to 2020: A data-driven analysis in the early phase of the outbreak. Int J Infect Dis 2020 Mar;92:214-217 [FREE Full text] [doi: 10.1016/j.ijid.2020.01.050] [Medline: 32007643]

37. Muniz-Rodriguez K, Chowell G, Cheung C, Jia D, Lai P, Lee Y, et al. Doubling Time of the COVID-19 Epidemic by Province, China. Emerg Infect Dis 2020 Aug;26(8):1912-1914 [FREE Full text] [doi: 10.3201/eid2608.200219] [Medline: 32330410]

38. Yuan Z, Xiao Y, Dai Z, Huang J, Zhang Z, Chen Y. Modelling the effects of Wuhan's lockdown during COVID-19, China. Bull World Health Organ 2020 May 28;98(7):484-494. [doi: 10.2471/blt.20.254045]

39. Jin H, Wang H, Li X, Zheng W, Ye S, Zhang S, et al. Economic burden of COVID-19, China, January-March, 2020: a cost-of-illness study. Bull World Health Organ 2021 Feb 01;99(2):112-124 [FREE Full text] [doi: 10.2471/BLT.20.267112] [Medline: 33551505]

40. Lee W, Hwang S, Song I, Park C, Kim H, Song I, et al. COVID-19 in South Korea: epidemiological and spatiotemporal patterns of the spread and the role of aggressive diagnostic tests in the early phase. Int J Epidemiol 2020 Aug 01;49(4):1106-1116 [FREE Full text] [doi: 10.1093/ije/dyaa119] [Medline: 32754756]

41. Hong K, Yum S, Kim J, Chun BC. The Serial Interval of COVID-19 in Korea: 1,567 Pairs of Symptomatic Cases from Contact Tracing. J Korean Med Sci 2020 Dec 28;35(50):e435 [FREE Full text] [doi: 10.3346/jkms.2020.35.e435] [Medline: 33372427]

42. Shim E, Tariq A, Chowell G. Spatial variability in reproduction number and doubling time across two waves of the COVID-19 pandemic in South Korea, February to July, 2020. Int J Infect Dis 2021 Jan;102:1-9 [FREE Full text] [doi: 10.1016/j.ijid.2020.10.007] [Medline: 33038555]

43. Peck K. Early diagnosis and rapid isolation: response to COVID-19 outbreak in Korea. Clin Microbiol Infect 2020 Jul;26(7):805-807 [FREE Full text] [doi: 10.1016/j.cmi.2020.04.025] [Medline: $\underline{\text { 32344168] }}$ 
44. Kwon KT, Ko J, Shin H, Sung M, Kim JY. Drive-Through Screening Center for COVID-19: a Safe and Efficient Screening System against Massive Community Outbreak. J Korean Med Sci 2020 Mar 23;35(11):e123 [FREE Full text] [doi: 10.3346/jkms.2020.35.e123] [Medline: 32193904]

45. Choi Y, Kim JS, Choi H, Lee H, Lee CH. Assessment of Social Distancing for Controlling COVID-19 in Korea: An Age-Structured Modeling Approach. Int J Environ Res Public Health 2020 Oct 14;17(20):7474 [FREE Full text] [doi: 10.3390/ijerph17207474] [Medline: 33066581]

46. Bertozzi AL, Franco E, Mohler G, Short MB, Sledge D. The challenges of modeling and forecasting the spread of COVID-19. Proc Natl Acad Sci U S A 2020 Jul 21;117(29):16732-16738 [FREE Full text] [doi: 10.1073/pnas.2006520117] [Medline: 32616574]

\title{
Abbreviations \\ MERS: Middle East respiratory syndrome \\ SARS: severe acute respiratory syndrome \\ WHO: World Health Organization
}

\author{
Edited by T Sanchez, G Eysenbach; submitted 29.12.20; peer-reviewed by TJ Chen, J Walsh; comments to author 25.01.21; revised \\ version received 28.02.21; accepted 24.03.21; published 01.06.21 \\ Please cite as: \\ Lee H, Kim Y, Kim E, Lee $S$ \\ Risk Assessment of Importation and Local Transmission of COVID-19 in South Korea: Statistical Modeling Approach \\ JMIR Public Health Surveill 2021;7(6):e26784 \\ URL: https://publichealth.jmir.org/2021/6/e26784 \\ doi: $10.2196 / 26784$ \\ PMID: 33819165
}

CHyojung Lee, Yeahwon Kim, Eunsu Kim, Sunmi Lee. Originally published in JMIR Public Health and Surveillance (https://publichealth.jmir.org), 01.06.2021. This is an open-access article distributed under the terms of the Creative Commons Attribution License (https://creativecommons.org/licenses/by/4.0/), which permits unrestricted use, distribution, and reproduction in any medium, provided the original work, first published in JMIR Public Health and Surveillance, is properly cited. The complete bibliographic information, a link to the original publication on https://publichealth.jmir.org, as well as this copyright and license information must be included. 